\title{
Heat transfer deterioration of aviation kerosene flowing in mini tubes at supercritical pressures
}

\author{
Dan Huang ${ }^{1, *}$, Wei Li $^{2}$ \\ ${ }^{1}$ Department of Mechanical and Electrical Engineering, Central South University of Forestry \\ and Technology University, Changsha 410004, China \\ ${ }^{2}$ Department of Energy Engineering, Zhejiang University, Hangzhou 310027, China \\ * Corresponding author, Tel: +86-85623096; Fax: +86-85623038; E-mail:
}

hiwactb@163.com

\begin{abstract}
Heat transfer performances of aviation kerosene flowing in mini tubes at supercritical pressures were investigated experimentally and numerically. A ten-species surrogate model with the extended correponding state was used to calculate the thermophysical and transport properties of kerosene and the Re-Normalization Group (RNG) $k-\varepsilon$ turbulent model with the enhanced wall treatment was adopted to consider the turbulent effect. The numerical results agree well with the experimental data. Two types of heat transfer deterioration were observed in this paper. The first type of deterioration occurs at the place where the wall temperature exceeds the pseudo-critical temperature, while the second type occurs when the bulk fluid temperature exceeds the pseudo-critical temperature. The effects of several key parameters, such as mass flow rate, heat flux, pressure and inlet temperature on heat transfer deterioration were studied in detail. The results reveal that the heat transfer coefficient increases with increasing mass flow rate and inlet temperature. The effect of heat flux on heat transfer is complicated, while the effect of pressure on heat transfer is insignificant. Heat transfer deterioration can be effectively eliminated by increasing mass flow rate and pressure and decreasing heat flux and inlet temperature. The dramatic variation of thermo-physical properties is the main reason for the heat transfer deterioration.
\end{abstract}

Keywords: aviation kerosene; heat transfer; supercritical pressure; heat transfer deterioration; parametric effects 


\section{Nomenclature}

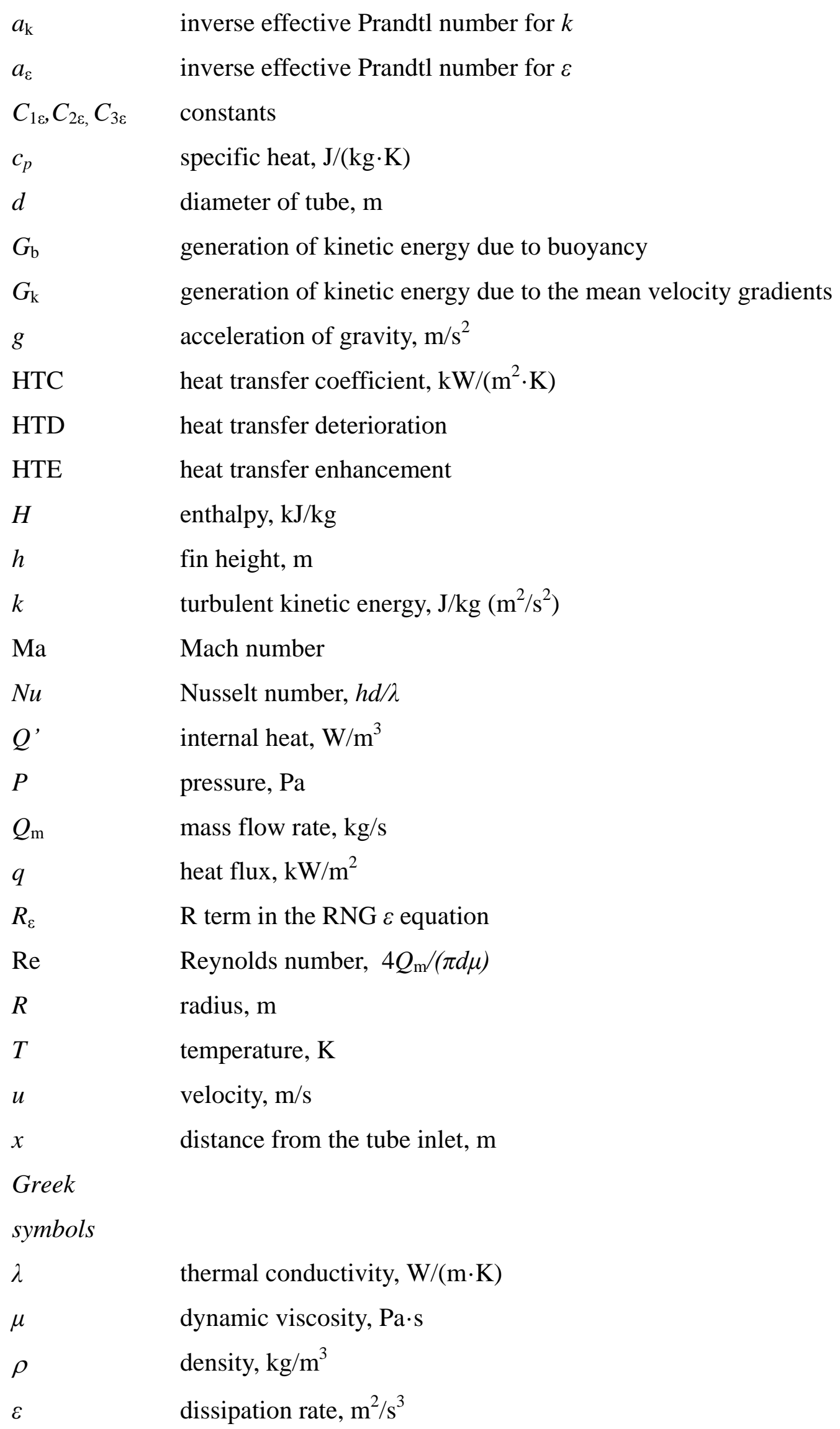




\section{Subscripts}

$\begin{array}{ll}\text { c } & \text { critical } \\ \text { cal } & \text { calculated } \\ \text { exp } & \text { experimental } \\ \mathrm{f} & \text { bulk fluid } \\ \text { i } & \text { inner } \\ \text { in } & \text { inlet } \\ \text { o } & \text { outer } \\ \text { pc } & \text { pseudo-critical } \\ \text { theo } & \text { theoretical } \\ \text { w } & \text { wall } \\ \text { X } & \text { local value }\end{array}$

\section{Introduction}

As the speed of flight systems increases to the supersonic and hypersonic regimes (Ma > 5), the compressor delivery temperature of fluid increases, and therefore, the cooling efficiency decreases and the turbine components suffer more and more thermal stress and heat load. Maintenance of safe working temperature by dissipating heat is essential for turbine performance and lifetime. To improve the cooling efficiency of heat transfer systems, the regenerative cooling system, where engine fuel works as a coolant and travels through the cooling tubes along the chamber wall, is developed as an effective thermal management technique ${ }^{[1-3]}$.

Aviation kerosene is a universal jet fuel for scramjet engines. Technically, the working pressure of the aviation kerosene in the cooling process is higher than its critical pressure and thus leading to supercritical-pressure fluid flow and heat transfer phenomena ${ }^{[4]}$. The major concern using supercritical aviation kerosene as working fluid is the heat transfer characteristics due to dramatic variations of thermo-physical properties near pseudo-critical temperature ( $T_{\mathrm{pc}}$, where the $c_{p}$ reaches the maximum value at $P>P_{\mathrm{c}}$ ). The special heat transfer performances of supercritical fluids have been extensively investigated since $1950 \mathrm{~s}{ }^{[5-8]}$. However, the investigations on heat transfer characteristics of supercritical hydrocarbon fuels are limited compared to those of simple fluids, such as water and carbon dioxide ${ }^{[9-11]}$. Li et al. ${ }^{[12]}$ experimentally investigated the heat transfer performance of China RP-3 aviation kerosene in a vertical smooth tube at supercritical pressures. Their results showed that heat transfer 
coefficient increased with increasing heat fluxes or inlet temperatures, but decreased with increasing inlet pressures. Zhu et al ${ }^{[13]}$ numerically studied the heat transfer characteristics and flow resistance of kerosene at supercritical pressures. They found that the local Nusselt number first increased and then suddenly dropped at a certain point. The pressure drop under different pressures were almost the same when the fuel temperature was lower than the critical teperature, while the diversity of pressure drop under variarous pressures became manifest when the fuel temperature was higher than the critical temperature.

At supercritical pressures, either heat transfer enhancement (HTE) or heat transfer deterioration (HTD) may occur. Some of the experiments observed no heat transfer deterioration, but Zhu et al. ${ }^{[13]}$, Dang et al. ${ }^{[14]}$, Zhao et al. ${ }^{[15]}$ and Li et al. ${ }^{[16]}$ did. They found the deterioration of the heat transfer occurred when the inner wall temperature or the fluid temperature was close to the pseudo-critical point. In the literatures, there are several explanations for the mechanism of heat transfer deterioration. HTD can be caused by intensive variations of thermo-physical properties, buoyancy effect, flow acceleration or combination of these factors. Researchers also made a lot of efforts to determine the onset of heat transfer deterioration. Yin et al. ${ }^{[17]}$ conducted experimental study on heat transfer of supercritical water. The critical value of ratio of wall heat flux to mass flux for the onset of heat transfer deterioration was also discussed. Kim et al. ${ }^{[18]}$ proposed a HTD correlation, $q=$ $0.0002 G^{2}\left(q: \mathrm{kW} / \mathrm{m}^{2}, G: \mathrm{kg} /\left(\mathrm{m}^{2} \mathrm{~s}\right)\right)$, based on the experimental data of $\mathrm{CO}_{2}$ at different geometries including circular, equilateral triangular and square cross-section channels and it predicted the experimental data well. Mokry ${ }^{[19]}$ collected a large set of experimental data of supercritical water and studied the flow and wall heat flux conditions for the occurrence of heat transfer deterioration. They also developed a correlation, $q=-58.97+0.745 G\left(q: \mathrm{kW} / \mathrm{m}^{2}\right.$, $\left.G: \mathrm{kg} /\left(\mathrm{m}^{2} \mathrm{~s}\right)\right)$, to predict the critical heat flux.

The comparison of some existing HTD criteria have been presented by Huang ${ }^{[20]}$ and differences have been indicated. For example, the correlation proposed by Kim et al. ${ }^{[18]}$ predicts the experimental data of $\mathrm{CO}_{2}$ well, however, it significantly underestimates the deteriorated heat flux of water. This indicates that the correlation developed based on one fluid cannot be applied directly to another fluid. As far as the authors know, there are few heat transfer deterioration correlations based on the experimental data of hydrocarbon fuels. Since the property variations of hydrocarbon fuels differ from those of carbon dioxide and water, it is also not appropriate to apply the criteria from carbon dioxide and water to hydrocarbon fuels. Thus, further investigations on heat transfer of hydrocarbon fuels are needed.

Besides, since hydrocarbon fuel is composed of several hundred species, modeling their 
thermo-physical properties and numerical simulation of their heat transfer performances are difficult, as a result, there are only a few relevant numerical studies available in the open literature. As the simulation work can help to obtain detailed information on the flow and heat transfer performances of hydrocarbon fuels at supercritical pressures, it is useful to conduct numerical studies.

In this paper, the heat transfer characteristics of aviation kerosene at supercritical pressures were investigated experimentally and numerically. The heat transfer deterioration was observed clearly by numerical simulation and the results were compared with the experimental data to identify the physical phenomenon of heat transfer deterioration. The key parameters, such as mass flow rate, heat flux, inlet temperature and pressure on heat transfer deterioration were also presented. Two types of heat transfer deterioration were discussed in detail.

\section{Experimental apparatus}

\subsection{Experimental loop}

The measured critical pressure and temperature of aviation kerosene are $2.4 \mathrm{MPa}$ and $373{ }^{\circ} \mathrm{C}{ }^{[16]}$, respectively. The experimental loop, as shown in Fig. 1, was constructed to operate at high temperature $\left(600{ }^{\circ} \mathrm{C}\right)$ and high pressure $(10 \mathrm{MPa})$. The fuel stored in the tank was circulated and compressed by a piston pump and then heated to the required inlet temperature in the preheating section under proper heat flux by the direct current power supplied on the stainless tube. After that, the fuel was sent to the test section, being heated and tested at supercritical condition and then was condensed, recollected and fed into the reservoir manually. The test tube is a vertical stainless steel tube with inner diameter of $1.8 \mathrm{~mm}$ and outer diameter of $3.0 \mathrm{~mm}$. The heated section of the test tube is $1000 \mathrm{~mm}$ long, and the two unheated sections (each with a length of $100 \mathrm{~mm}$, i.e., $50 \mathrm{~d}$ ) are located before and after the heated section. A low-voltage direct-current power was used to heat the test section and simulate constant heat flux condition. The inlet and outlet temperatures of the test section were carefully obtained using armored K-type thermocouples (Accuracy: 0.4\%). The local wall temperatures of the test section were measured by $12 \mathrm{~K}$-type thermocouples $(\phi 0.3 \mathrm{~mm})$, which were carefully welded onto but insulated with the tube outer surface. The working pressure was measured by using a pressure gauge transducer (Accuracy: $0.075 \%$ of the full range of $12 \mathrm{MPa}$ ). The mass flow rate was measured by a Coriolis mass flow meter (Accuracy: $0.2 \%$ of the full range of $60 \mathrm{~kg} / \mathrm{h}$ ). Details of the control parameters and operation of the 
experimental loop were given in Ref. [16].

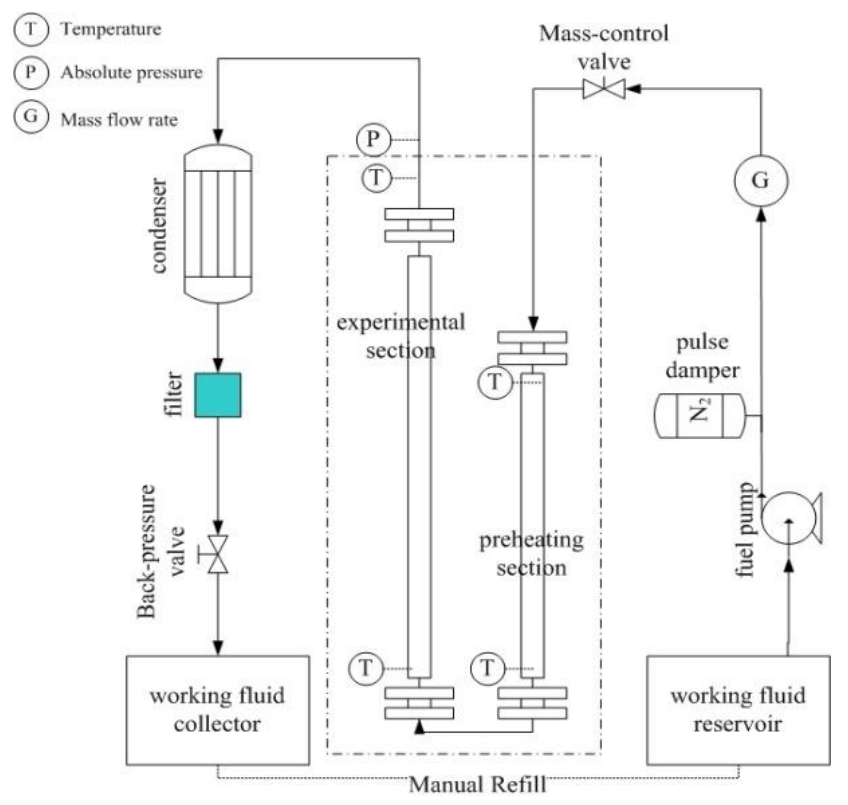

Fig. 1 Schematic of the experimental setup

\subsection{Data reduction}

The local inner wall temperature, $T_{\mathrm{wi}, \mathrm{x}}$, can be deduced from the outer wall temperature $\left(T_{\mathrm{wo}, \mathrm{x}}\right)$ by assuming one-dimensional heat conduction with an internal heat source $\left(Q^{\prime}\right)$ as:

$$
T_{w i, x}=T_{w o, x}+\frac{1}{4} \frac{Q^{\prime}}{\lambda}\left(R_{o}^{2}-R_{i}^{2}\right)+\frac{1}{2} \frac{Q^{\prime}}{\lambda} R_{o}^{2} \ln \frac{R_{i}}{R_{o}}
$$

The local heat transfer coefficient (HTC) along the tube length was calculated by the following equation:

$$
h_{x}=\frac{q_{n e t}}{T_{w i, x}-T_{f, x}}
$$

where $T_{\mathrm{f}, \mathrm{x}}$ is the local fuel temperature and can be calculated from the local enthalpy $(H)$, heat flux $(q)$ and mass flux $(G) ; q_{\text {net }}$ is the net heat flux and can be calculated by:

$$
q_{\text {net }}=q_{x}-q_{\text {loss }}=\frac{U I}{\pi D_{i} L}-q_{\text {loss }}
$$

where $q_{\mathrm{x}}$ was the total heat flux input, $q_{\text {loss }}$ was the heat loss at the experimental section, which was obtained experimentally. The electric power input to the tube was considered to be almost the same as the heat loss when there was no flowing fluid through it. By varying the heating power, the heating power input and the outer wall temperature can be obtained at steady state. The heat loss was then correlated as a function of the outer wall temperature. $Q_{\text {loss }}$ was tested to be lower than $5 \%$ of the electric power input to the test section.

Table 1 briefly summarizes the operating conditions for all experiments. The relative 
errors for measurement and accumulated errors by calculations are listed in Table 2 .

Table 1 Operating parameters

\begin{tabular}{lllll}
\hline Direction & Mass flow rate & Heat flux & Pressure & Inlet temperature \\
\hline Upward & $2-2.6 \mathrm{~g} / \mathrm{s}$ & $190-300 \mathrm{~kW} / \mathrm{m}^{2}$ & $3-4 \mathrm{MPa}$ & $408-448 \mathrm{~K}$ \\
\hline
\end{tabular}

Table 2 Error analysis

\begin{tabular}{ll}
\hline Item & Error $(\%)$ \\
\hline Temperature difference & 5.3 \\
Pressure & 0.36 \\
Mass flow rate & 1.67 \\
Heat flux & 3.1 \\
Heat transfer coefficient & 6.14 \\
\hline
\end{tabular}

\subsection{Validation of the test rig}

In order to verify the accuracy and reliability of the test rig, preliminary experiments were performed at $2.5 \mathrm{MPa}$ by using deionized water. The Gnielinski equation ${ }^{[21]}$ was used to predict the experimental data of water. Figure 2 shows that the calculated result agrees well with the experimental data.
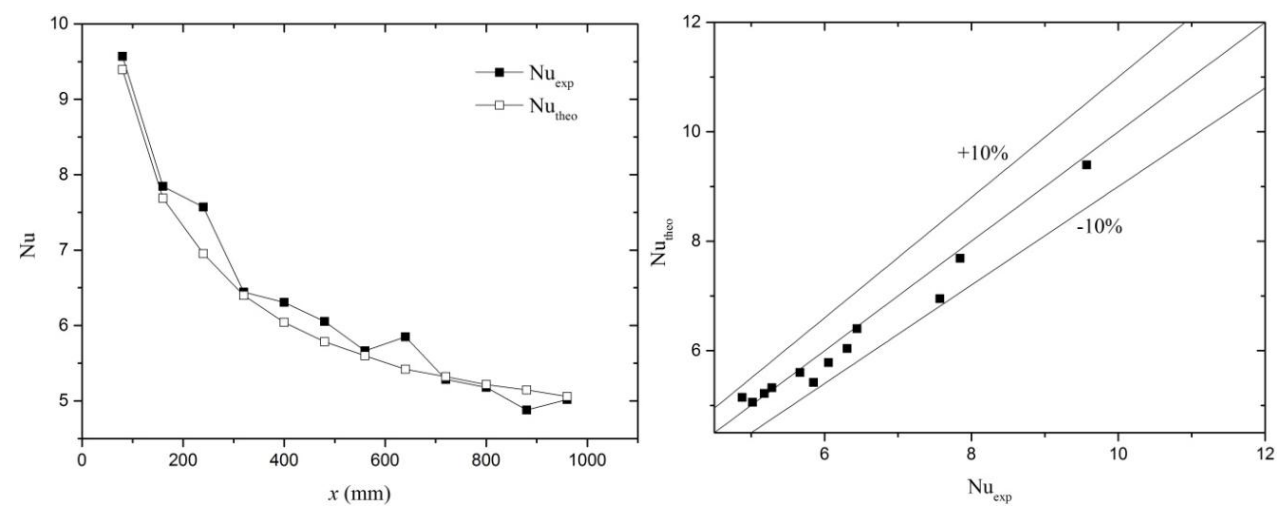

Fig. 2 Comparison of $\mathrm{Nu}$ of water between experimental data and predictive values

\section{Numerical methods}

\subsection{Governing equations and solution methods}

Mass conservation:

$$
\frac{\partial}{\partial x_{i}}\left(\rho u_{i}\right)=0
$$

Momentum conservation:

$$
\frac{\partial}{\partial x_{j}}\left(\rho u_{i} u_{j}\right)=\frac{\partial}{\partial x_{j}}\left[\mu_{e}\left(\frac{\partial u_{i}}{\partial x_{j}}+\frac{\partial u_{j}}{\partial x_{i}}\right)-\frac{2}{3} \mu_{e} \frac{\partial u_{k}}{\partial x_{k}}\right]-\frac{\partial P}{\partial x_{i}}+\rho g_{i}
$$

The energy conservation: 


$$
\frac{\partial}{\partial x_{i}}\left(\rho u_{i} c_{p} T\right)=\frac{\partial}{\partial x_{i}}\left(\lambda_{e} \frac{\partial T}{\partial x_{i}}\right)+\frac{\partial u_{i}}{\partial x_{j}}\left[\mu_{e}\left(\frac{\partial u_{i}}{\partial x_{j}}+\frac{\partial u_{j}}{\partial x_{i}}\right)-\frac{2}{3} \mu_{e} \frac{\partial u_{k}}{\partial x_{k}} \delta_{i j}\right]
$$

RNG $k$ turbulence equation:

$$
\frac{\partial}{\partial x_{i}}\left(\rho u_{i} k\right)=\frac{\partial}{\partial x_{i}}\left(a_{k} \mu_{e} \frac{\partial k}{\partial x_{i}}\right)+G_{k}+G_{b}-\rho \varepsilon
$$

Turbulent kinetic energy dissipation ratio:

$$
\frac{\partial}{\partial x_{i}}\left(\rho u_{i} \varepsilon\right)=\frac{\partial}{\partial x_{i}}\left(a_{\varepsilon} \mu_{e} \frac{\partial \varepsilon}{\partial x_{i}}\right)+C_{1 \varepsilon} G_{k} \frac{\varepsilon}{k}+C_{3 \varepsilon} G_{b} \frac{\varepsilon}{k}-C_{2 \varepsilon} \rho \frac{\varepsilon^{2}}{k}-R_{\varepsilon}
$$

where $\mu_{e}=\mu\left(1+\sqrt{\frac{C_{\mu}}{\mu}} \frac{k}{\sqrt{\varepsilon}}\right)^{2}, a_{k}, a_{\varepsilon}$ and $a$ can be obtained from the equation:

$$
\left|\frac{a-1.3929}{a_{0}-1.3929}\right|^{0.6321}\left|\frac{a+2.3929}{a_{0}+2.3929}\right|^{0.3679}=\frac{\mu}{\mu_{e}}
$$

where the values of $a_{0}$ are $1.0,1.0$ and $1 / \mathrm{Pr}$, respectively.

$G_{\mathrm{k}}$, representing the production of turbulence kinetic energy, can be defined as:

$$
G_{k}=-\rho \overline{u_{i}^{\prime} u_{j}^{\prime}} \frac{\partial u_{j}}{\partial x_{i}}
$$

$G_{\mathrm{k}}$, representing the generation of turbulence due to buoyancy, can be defined as:

$$
G_{b}=-a g \frac{\mu_{t}}{\rho} \frac{\partial T}{\partial x_{i}}\left(\frac{\partial \rho}{\partial T}\right)_{p}
$$

The pressure-based solver in FLUENT 14.0 was adopted to solve the governing equations for the flow and heat transfer of aviation kerosene at supercritical pressures. The convection term was discretized with the second-order upwind difference scheme and the diffusion term was handled by the second-order central difference scheme. The SIMPLEC algorithm was employed to resolve the coupling between velocity and pressure. RNG $k-\varepsilon$ model with enhanced wall treatment is adopted to predict the turbulent fluid flow and heat transfer at supercritical pressures. RNG $k-\varepsilon$ turbulence model ${ }^{[22]}$ is widely used in the simulation of supercritical aviation kerosene due to its relatively high accuracy in dealing with rapid variations of thermo-physical properties ${ }^{[2-24]}$. In order to achieve the required precision for the computational data, the distance of the wall-adjacent cell to the wall should be controlled to fit the requirement of $y^{+} \leq 1$ in the calculation domain. At the same time, there should be at least 10 cells within the viscosity-affected near-wall region to satisfy the calculation precision in that region.

\subsection{Thermo-physical properties evaluations}


The density $(\rho)$, specific heat $\left(c_{\mathrm{p}}\right)$, thermal conductivity $(\lambda)$ and viscosity $(\mu)$ of the aviation kerosene at various temperatures were obtained by a 10 -species surrogate and the NIST Supertrapp software. The component and mole fraction of the surrogate are listed in Table 3. Figure 3 shows the comparison of numerical data and experimental data ${ }^{[25-28]}$ for the thermo-physical properties of aviation kerosene at $P=3 \mathrm{MPa}$. Good agreement has been reached between the calculated results and experimental data at $P=3 \mathrm{MPa}$. For density calculation, the largest difference is within $7 \%$; for thermal conductivity, it is within $10 \%$; for viscosity, it is within 5\%; for heat capacity, the largest difference slightly increases to around $18 \%$.

Table 3 10-species surrogate of aviation kerosene

\begin{tabular}{ccc}
\hline & Composition & Molar fraction (\%) \\
\cline { 2 - 2 } Alkanes & n-Octane & 6 \\
& n-Decane & 10 \\
n-Dodecane & 20 \\
n-Tridecane & 8 \\
n-Tetradecane & 10 \\
& n-Hexadecane & 10 \\
Methylcyclohexane & 20 \\
Cycloalkanes & Trans-1,3-Dimethylcyclopentane & 8 \\
& Propylbenzene & 5 \\
Benzenes & 1-Methylnaphthalene & 3
\end{tabular}

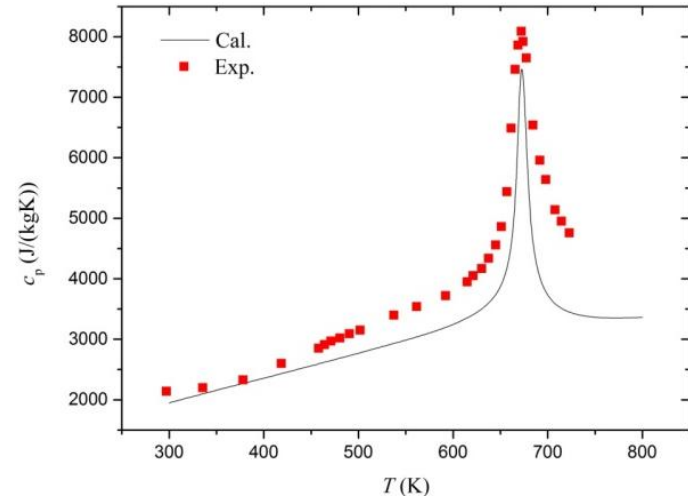

(a) specific heat

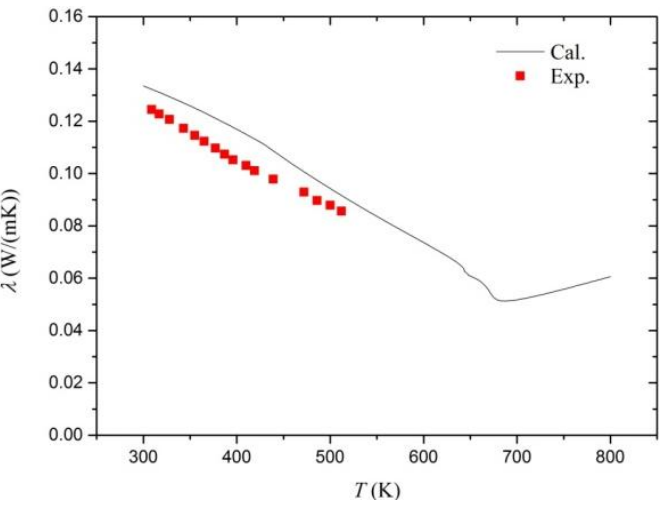

(b) thermal conductivity 


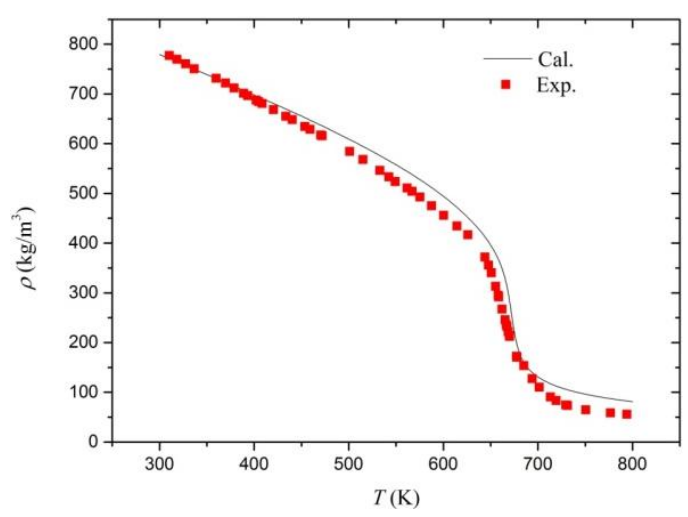

(c) density

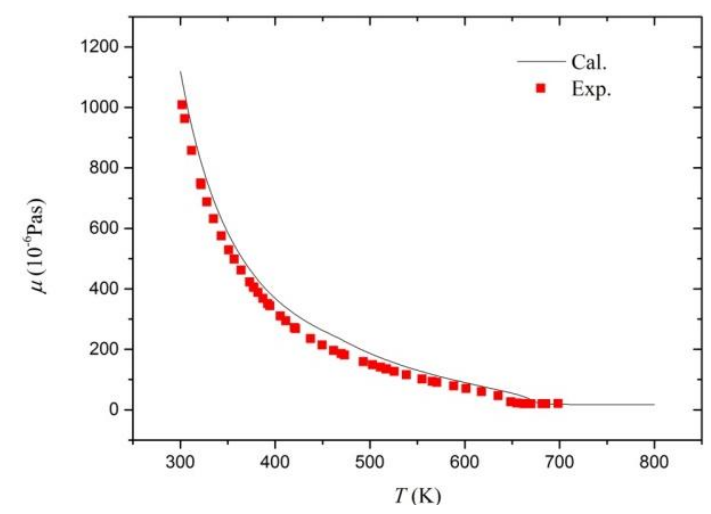

(d) viscosity

Fig. 3 Comparison of numerical data and experimental data for the thermo-physical properties of aviation kerosene at $P$ $=3 \mathrm{MPa}$

\subsection{Validation of numerical methods}

A three-dimensional computational domain was employed to represent the physical model and the boundary conditions were in accordance with the experimental conditions. A given temperature and mass flow rate of turbulent pipe flow were imposed as the inlet boundary condition. The inlet turbulence intensity was set as $5.0 \%$. The outlet boundary condition was set as outflow boundary. The no slip and no penetration boundary was used for the pipe wall and a constant wall heat flux was set as the thermal boundary condition. Before the detailed numerical studies, the grid independence was checked. Three meshes were constructed. When the deviation in the results obtained with the three meshes was less than $1 \%$, the simulation result was considered to be independent of the grids. A total grid number of 1921040 was proved to be computational efficient and accurate. Figure 4 shows the grids of the cross section.

The accuracy and reliability of the present computation method was also checked. The calculated results by using the current method were compared with the experimental data of supercritical aviation kerosene ${ }^{[4]}$. The inlet pressure and temperature are $5 \mathrm{MPa}$ and $400 \mathrm{~K}$, respectively. The mass flow rate is $2 \mathrm{~g} / \mathrm{s}$ and the inlet Reynolds number is 7000 . The wall heat flux ranges from 101.77 to $392.89 \mathrm{~kW} / \mathrm{m}^{2}$. Figure 5 gives distribution of fluid temperature and wall temperature along the tube length with present computation and experimental measurements. As shown in the figure, the numerical results agree well with the experimental data. The maximum discrepancy of the wall temperature and the fluid temperature are less than $7 \%$, proving the accuracy of present numerical method. 


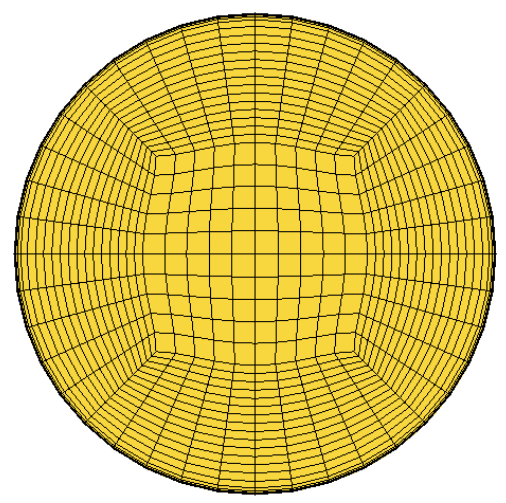

Fig. 4 Grids in the cross section
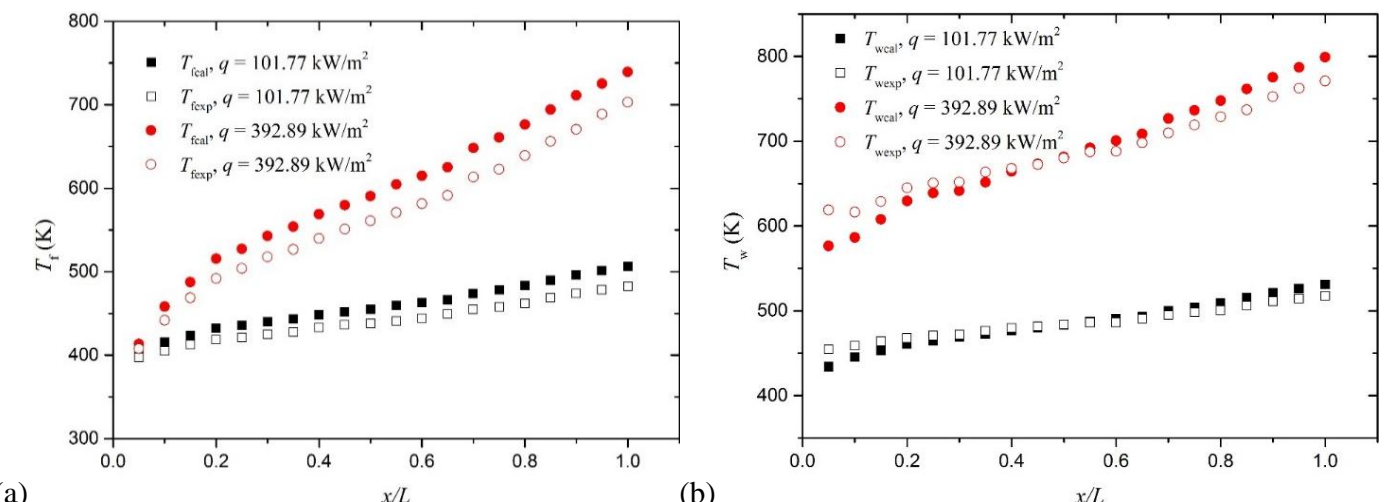

(b)

$x / L$

Fig.5 Comparison of temperatures between simulation results and experimental data in ref. [4] (a) fluid temperature (b) wall temperature

\section{Results and Discussion}

\subsection{Mass flow rate effects}

Figure 6 presents the experimental results of inner wall (solid symbols) and bulk fluid (hollow symbols) temperature distributions for various mass fluxes at $T_{\text {fin }}=143{ }^{\circ} \mathrm{C}, P=3$ MPa and $q=295 \mathrm{~kW} / \mathrm{m}^{2}$. The mass flow rate is $2,2.3,2.6 \mathrm{~g} / \mathrm{s}$, respectively and the corresponding Reynolds number is 4400, 5100 and 5800. Figure 7 depicts the variations of heat transfer coefficients.

The inner wall temperature decreases as mass flow rate increases and the heat transfer coefficient increases with increasing mass flow rate. This is because higher mass flow rate leads to higher Reynolds number and stronger turbulence and hence better heat transfer performance. As the fluid temperature increases along the tube, the dynamic viscosity decreases and thus the Reynolds number based on the fluid temperature increases significantly. It is found that Re increases by 1 order of magnitude, from 5800 at the inlet to 35000 near the outlet at $Q_{\mathrm{m}}=2.6 \mathrm{~g} / \mathrm{s}$.

However, it should be noted that for $Q_{\mathrm{m}}=2 \mathrm{~g} / \mathrm{s}$ and $Q_{\mathrm{m}}=2.3 \mathrm{~g} / \mathrm{s}$, heat transfer 
coefficient exhibits a decrease in the region of $560<x<720 \mathrm{~mm}$ and $720<x<800 \mathrm{~mm}$, respectively. The decrease in the heat transfer coefficient indicates the existence of heat transfer deterioration. Comparing Fig. 6 and Fig. 7, it is found that HTD starts to happen at the place where the inner wall temperature exceeds the pseudo-critical temperature. Due to the limitation of experimental apparatus, it is hard to measure the wall temperature and fluid temperature more intensively and accurately. Thus the numerical simulation was adopted to capture the heat transfer deterioration phenomenon.

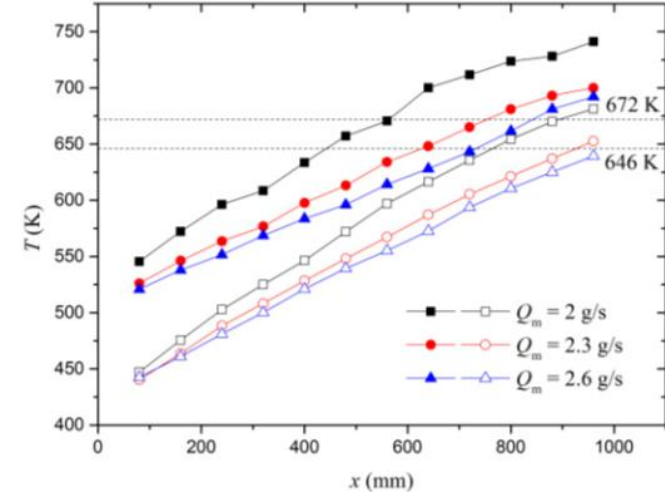

Fig. 6 Inner wall temperaturei (solid symbols) and fluid temperature (hollow symbols) distributions along tube length under various mass flow rates

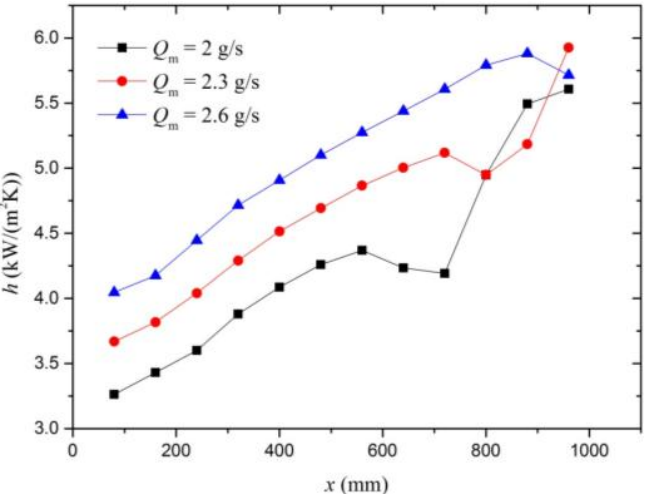

Fig. 7 Heat transfer coefficient distributions along the tube length under various mass flow rates

Figure 8 shows the comparison between numerical results and experimental data under different mass flow rates. The numerical data agrees well with the experimental data and the maximum discrepancy is within $10 \%$. Heat transfer deterioration is clearly observed at $Q_{\mathrm{m}}=2$ $\mathrm{g} / \mathrm{s}$ and $Q_{\mathrm{m}}=2.3 \mathrm{~g} / \mathrm{s}$ in Fig. 8. But the start point of HTD delayed at $Q_{\mathrm{m}}=2.3 \mathrm{~g} / \mathrm{s} \mathrm{compared}$ with $Q_{\mathrm{m}}=2 \mathrm{~g} / \mathrm{s}$. Figure 9 presents the numerical results of inner wall temperature, fluid temperature and heat transfer coefficient (defined as $h=q_{\mathrm{w}} /\left(T_{\mathrm{w}}-T_{\mathrm{f}}\right)$, where $q_{\mathrm{w}}$ is the heat flux imposed on the pipe wall, $T_{\mathrm{w}}$ is the wall temperature and $T_{\mathrm{f}}$ is the fluid temperature of aviation kerosene defined as $\left.T_{f}=\int \rho C_{\mathrm{p}} u T d A / \int \rho C_{\mathrm{p}} u d A\right)$ distributions at $Q_{\mathrm{m}}=2 \mathrm{~g} / \mathrm{s}$. It can be seen that the inner wall temperature exceeds the pseudo-critical temperature when HTD occurs, which is consistent with the experimental data. The specific heat $c_{\mathrm{p}}$ reaches the maximum value at pseudo-critical point. After that, $c_{\mathrm{p}}$ of near-wall fluid begins to decrease drastically and strongly reduces the heat transfer ability, as shown in Fig. 10. Besides, the thermal conductivity continually reduces with the increase in fluid temperature. As a result, heat transfer is deteriorated. Similar phenomena have been reported in the literatures $[13,14]$.

As the bulk fluid temperature continually increases along the tube length and approaches the pseudo-critical temperature, the thermo-physical properties of bulk fluid change 
dramatically. The specific heat increases and the viscosity decreases and thus the fluid velocity and Reynolds number both increase. These two factors significantly increase the turbulence, as a result, the heat transfer gradually recovers.

Figure 11 shows the mass flow rates effects on heat transfer deterioration. The smaller the mass flow rate is, the more serious the heat transfer deterioration is. The start point of HTD delays as the mass flow rate increases. When the mass flow rate increases to $3 \mathrm{~g} / \mathrm{s}, \mathrm{HTD}$ disappears.
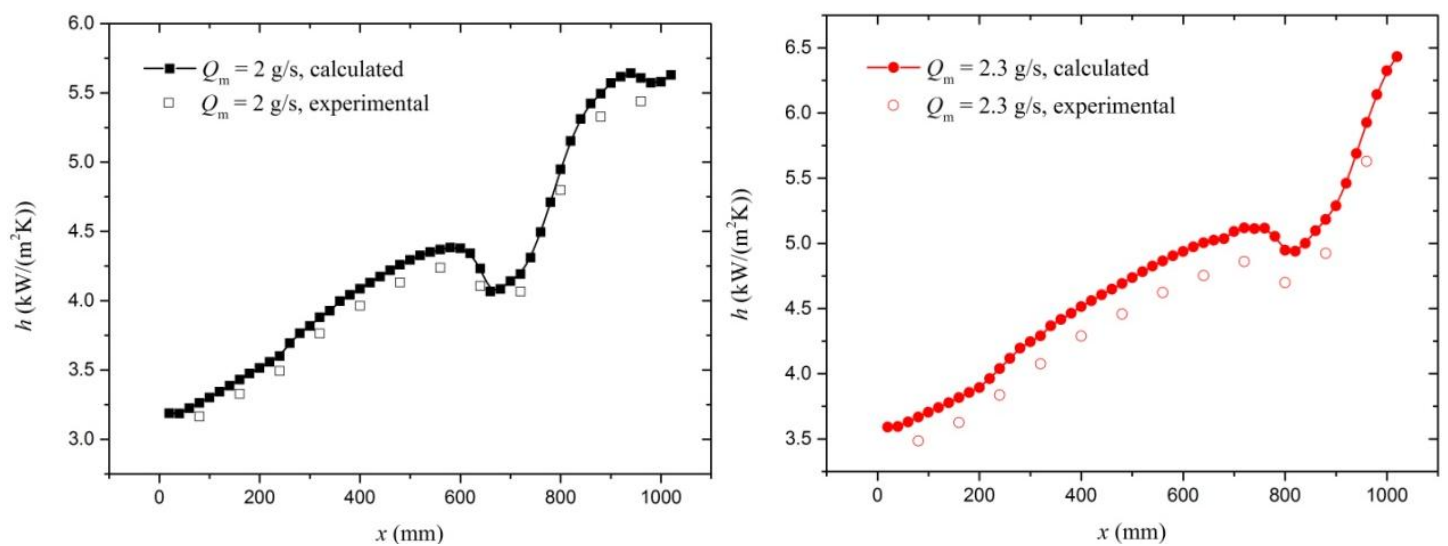

Fig. 8 Comparisons of heat transfer coefficients between numerical simulation and experimental data along the tube length under different mass flow rates

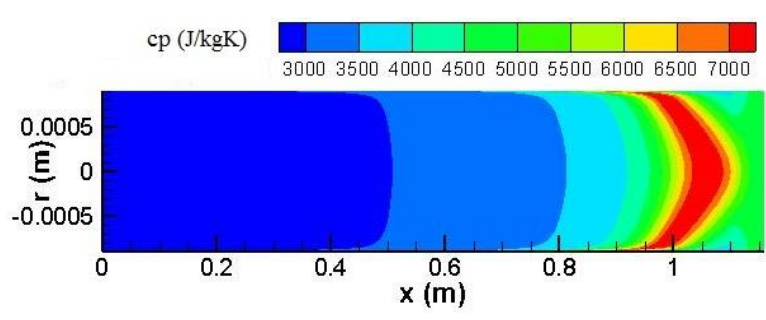

(a)

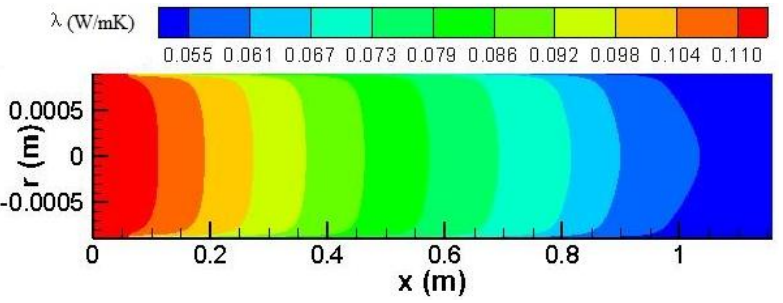

(b)

Fig. 10 Thermo-physical property distributions at $Q_{\mathrm{m}}=2 \mathrm{~g} / \mathrm{s}$,(a) heat capacity; (b) thermal conductivity

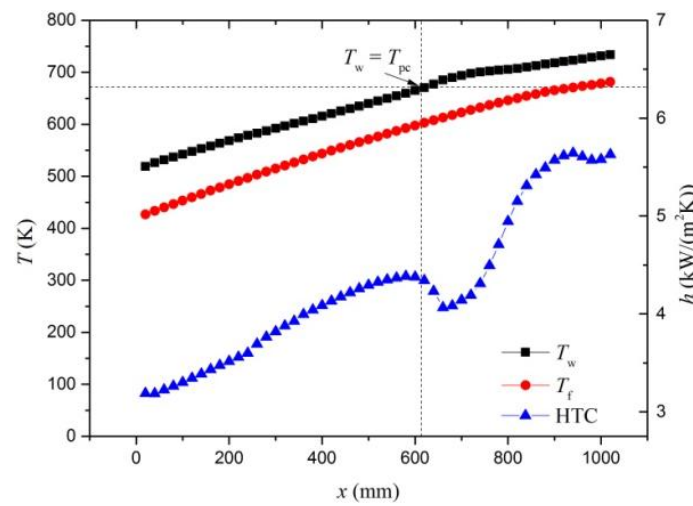

Fig. 9 Fluid temperature, wall temperature and heat transfer coefficient distributions along the tube length at $P=3 \mathrm{MPa}, \quad Q_{\mathrm{m}}=2 \mathrm{~g} / \mathrm{s}, \quad q=295 \mathrm{~kW} / \mathrm{m}^{2}, \quad T_{\text {fin }}=420 \mathrm{~K}$

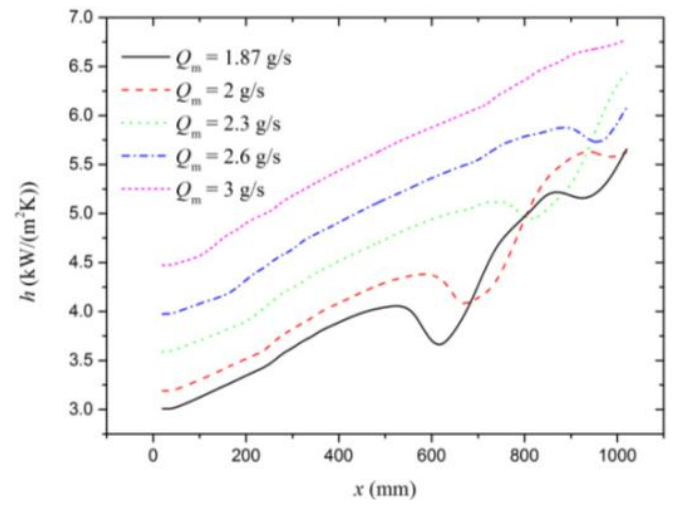

Fig. 11 Heat transfer deterioration under different mass flow rates 


\subsection{Heat flux effects}

As the variation of heat flux will influence the variation of wall temperature and fluid temperature, the thermo-physical properties will also be influenced. As a result, heat flux might have great influence on the heat transfer of aviation kerosene. Figure 12 presents the experimental results of temperature $\left(T_{\mathrm{wi}}\right.$ and $\left.T_{\mathrm{f}}\right)$ distributions for various heat fluxes at $P=3$ MPa, $Q_{\mathrm{m}}=2.22 \mathrm{~g} / \mathrm{s}$ and $T_{\text {fin }}=150{ }^{\circ} \mathrm{C}$. The heat flux is 277,319 and $355 \mathrm{~kW} / \mathrm{m}^{2}$, respectively. Figure 13 depicts the variations of corresponding heat transfer coefficients (HTC).

The wall temperature and fluid temperature both increases with increasing heat flux. On one hand, as the fluid temperature increases, the specific heat increases while the viscosity decreases and this will therefore enhance heat transfer. However, on the other hand, the wall temperature also increases with increasing heat flux. When the near-wall fluid temperature exceeds the pseudo-critical temperature, the specific heat of near-wall fluid will decrease dramatically and the thermal conductivity also decreases. Besides, the density decreases significantly along the flow direction, which may induce the flow acceleration effect. Flow acceleration is caused by the non-uniform density distribution across the axial direction and it has been widely investigated by researchers. He et al. [29] numerically investigated the convective heat transfer of carbon dioxide at supercritical pressures. They found the heat transfer was greatly impaired by the flow acceleration when the heating was strong. Jiang et al. [30] investigated the heat transfer of $\mathrm{CO}_{2}$ in a $0.27 \mathrm{~mm}$ vertical tube experimentally and numerically. The flow acceleration due to heating significantly influenced the turbulence and reduced the heat transfer at high heat fluxes. Under the flow acceleration effect, the near-wall fluid will be accelerated and hence the velocity difference between the near wall region and the center is decreased and consequently, the turbulence is reduced and heat transfer is deteriorated. The comprehensive effects of bulk fluid and near-wall fluid make the variations of heat transfer coefficients under different heat fluxes complicated.

From Fig. 13, we can see that the heat transfer coefficients seem to increase linearly and are almost the same under different heat fluxes at the former part of the tube. However, the difference of HTC at various heat fluxes increases at the latter part of the tube. Heat transfer is deteriorated in the region of $480<x<560 \mathrm{~mm}$ and $640<x<720 \mathrm{~mm}$ for $q=353 \mathrm{~kW} / \mathrm{m}^{2}$ and $q=319 \mathrm{~kW} / \mathrm{m}^{2}$, respectively. It is also found that the inner wall temperature exceeds the pseudo-critical temperature at the place where HTD occurs. 

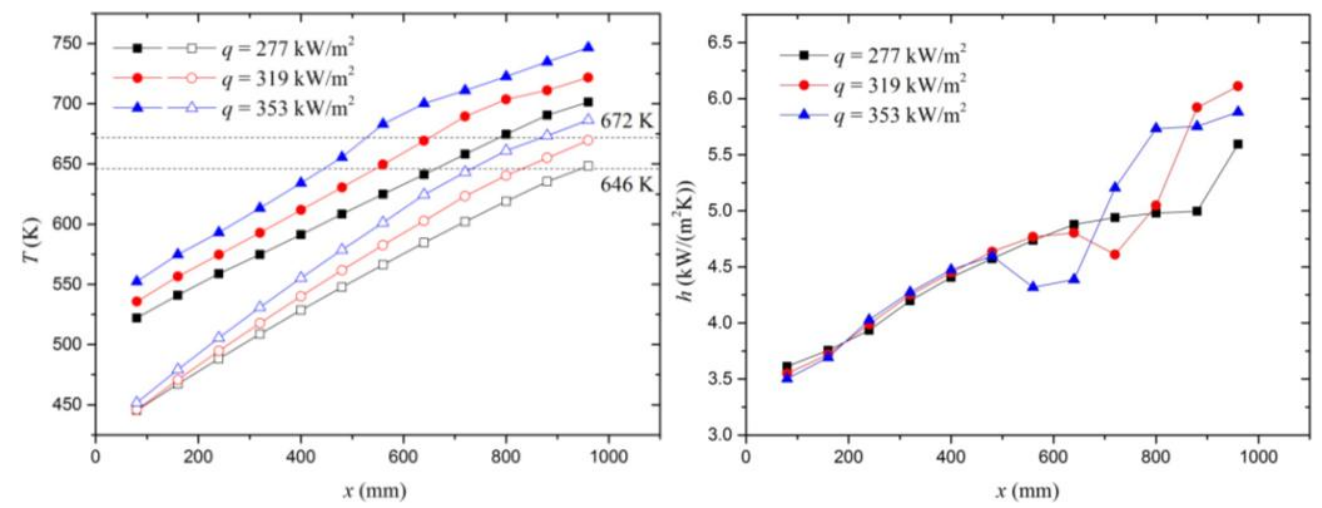

Fig. 12 Inner wall temperature (solid symbols) and fluid temperature (hollow symbols) distributions along

Fig. 13 Heat transfer coefficient distributions along the tube length under various heat fluxes the tube length under various heat fluxes

Figure 14 shows the comparison between numerical results and experimental data under different heat fluxes. The numerical data agrees well with the experimental data and the maximum discrepancy is within $10 \%$. Figure 15 presents the numerical results of inner wall temperature, fluid temperature and heat transfer coefficient distributions at $q=353 \mathrm{~kW} / \mathrm{m}^{2}$. When the inner wall temperature exceeds the pseudo-critical temperature, heat transfer deterioration occurs as expected. We call the first type of HTD as HTD I. The reason for HTD I was explained above. Then as the fluid temperature continually increases and approaches the pseudo-critical point, the thermo-physical properties change sharply, as shown in Fig. 16. The increase in the specific heat and the decrease in the viscosity make the heat transfer improved. However, when the fluid temperature increases to be larger than the pseudo-critical temperature, heat transfer coefficient decreases again. We call the second type of HTD as HTD II. As the fluid temperature exceeds the pseudo-critical temperature, the specific heat of bulk fluid begins to decreases and the thermal conductivity also decreases, which deteriorates the heat transfer. Besides, the inner wall temperature is much larger than the pseudo-critical temperature, thus the specific heat and thermal conductivity of near-wall fluid keep at a low value. As a result, heat transfer coefficient decreases. 

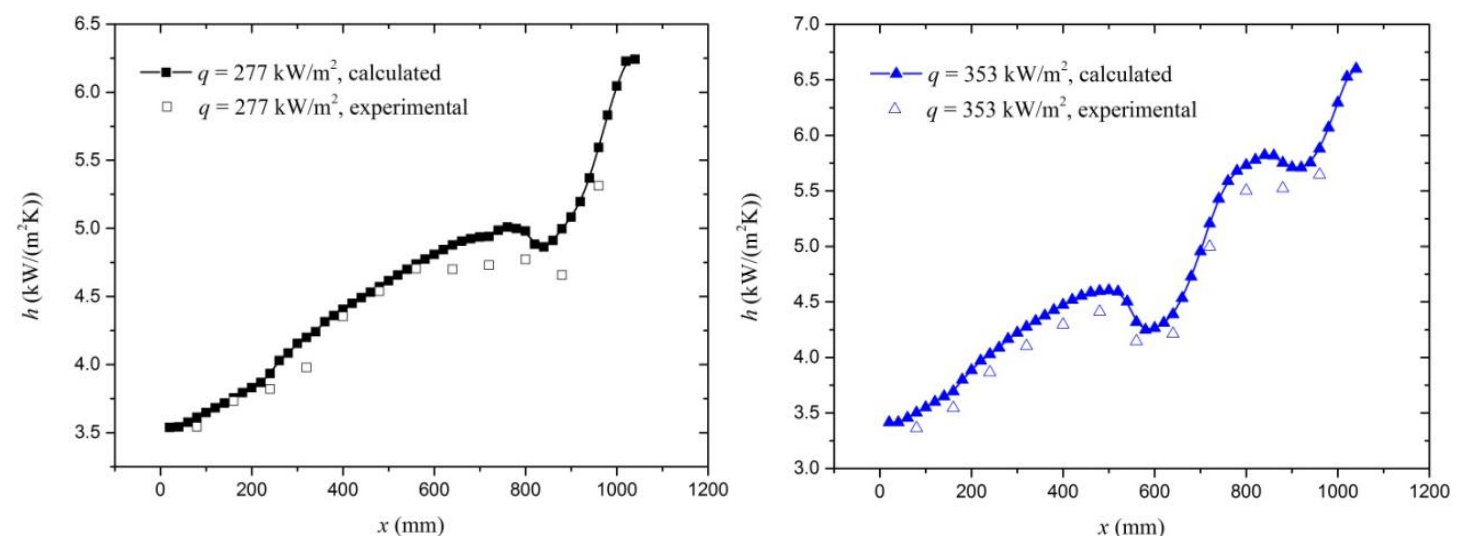

Fig. 14 Comparisons of heat transfer coefficients between numerical simulation and experimental data along the tube length under different heat fluxes

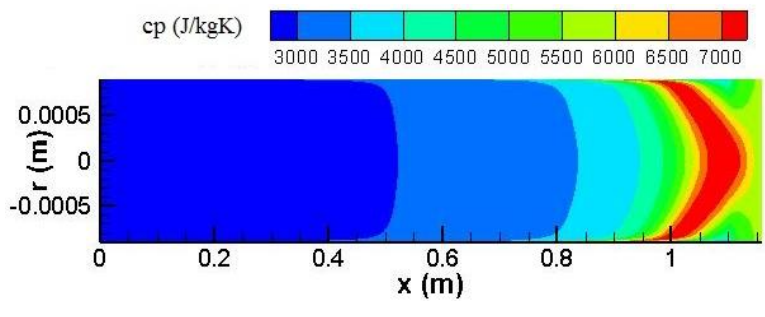

(a)

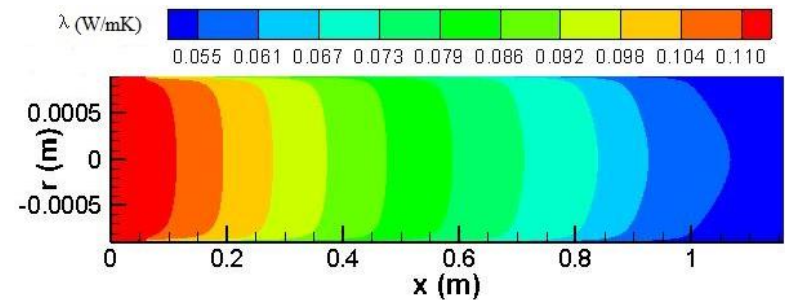

(b)

Fig. 16 Thermo-physical property distributions at $q=355 \mathrm{~kW} / \mathrm{m}^{2}$,(a) heat capacity; (b) thermal conductivity

Figure 17 shows the heat flux effect on heat transfer deterioration. The higher the heat flux is, the more serious the heat transfer deterioration is. The start point of HTD delays as the heat flux decreases. When the heat flux increases to $380 \mathrm{~kW} / \mathrm{m}^{2}$, two types of HTD are observed. However, when the heat flux decreases to $240 \mathrm{~kW} / \mathrm{m}^{2}$, no obvious HTD is observed.

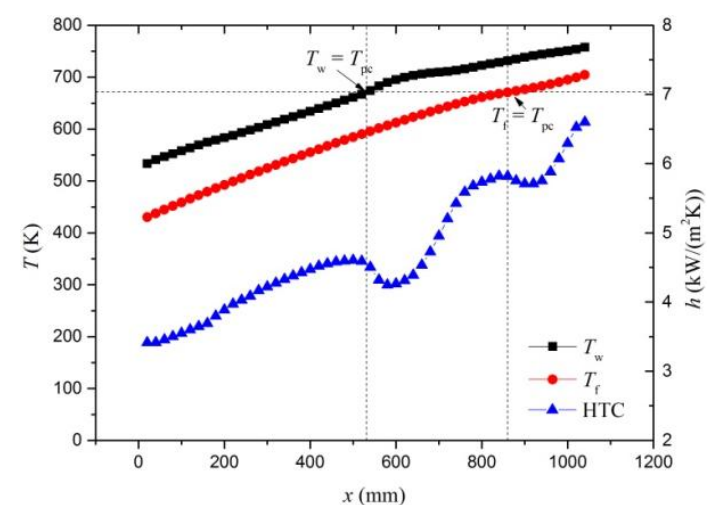

Fig. 15 Fluid temperature, wall temperature and heat transfer coefficient distributions along the tube length at $P$ $=3 \mathrm{MPa}, Q_{\mathrm{m}}=2.21 \mathrm{~g} / \mathrm{s}, \quad q=353 \mathrm{~kW} / \mathrm{m}^{2}, \quad T_{\text {fin }}=423 \mathrm{~K}$

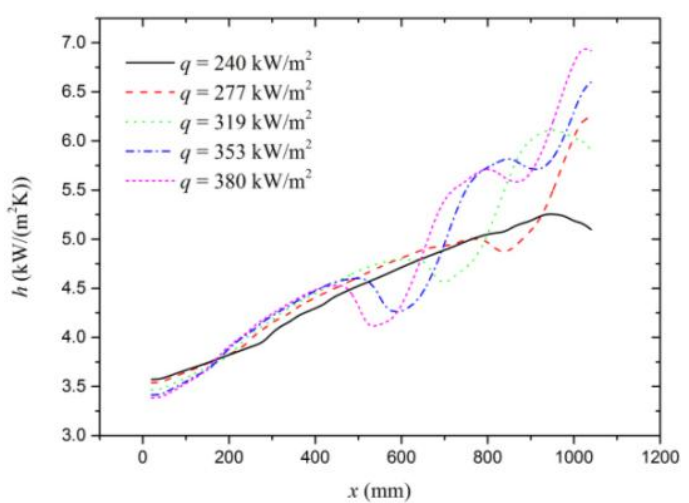

Fig. 17 Heat transfer deterioration under different heat fluxes

\subsection{Pressure effects}


From the thermo-physical properties of aviation kerosene (Fig. 18), we know that when the temperature of the kerosene is lower than critical temperature, pressure has little effect on the thermo-physical properties; yet at temperatures higher than critical temperature, increasing pressure leads to higher viscosity, higher thermal conductivity and higher pseudo-critical temperature. As the thermo-physical properties change with pressures, heat transfer performance might change as well.

Figure 19 shows the experimental results of wall temperature and fluid temperature distributions at pressures varying from 3 to $4 \mathrm{MPa}$ at $Q_{\mathrm{m}}=2.2 \mathrm{~g} / \mathrm{s}, q=319 \mathrm{~kW} / \mathrm{m}^{2}$ and $T_{\text {fin }}=$ $148{ }^{\circ} \mathrm{C}$. The wall temperature and fluid temperature distributions under various pressures are almost the same, as expected. Figure 20 presents the corresponding HTC distributions along the tube length and there is also no much difference in the HTCs under different pressures. Heat transfer coefficient decreases in the region of $480<x<620 \mathrm{~mm}$ at $P=3 \mathrm{MPa}$. Comparing Fig. 19 and Fig. 20, it is found that HTD starts to happen at the place where the inner wall temperature exceeds the pseudo-critical temperature.

Figure 21 shows the comparison between numerical results and experimental data under different pressures. The numerical data agrees well with the experimental data and the maximum discrepancy is within $10 \%$. Figure 22 presents the numerical results at $P=3 \mathrm{MPa}$. In the numerical results, two types of HTD are observed. When the inner wall temperature is larger than the pseudo-critical temperature, HTD I occurs. When the fluid temperature is larger than the pseudo-critical temperature, HTD II occurs. However, it should be noted that for $P=4 \mathrm{MPa}$, the inner wall temperature also exceeds the pseudo-critical temperature as shown in Fig. $19\left(T_{\mathrm{pc}}=720 \mathrm{~K}\right.$ for $\left.P=4 \mathrm{MPa}\right)$, but no obvious heat transfer deterioration is observed. Thus we assumed that the heat transfer deterioration is not only related to the temperature approaching the pseudo-critical temperature, but more related to the changes of thermo-physical properties. For $P=4 \mathrm{MPa}$, the variation of thermo-physical properties is small, thus the decrease of specific heat and thermal conductivity around the pseudo-critical point is not dramatic. As a result, heat transfer is not deteriorated.

The pressure effect on heat transfer deterioration is shown in Fig. 23. When the pressure increases to 4.5 and $5 \mathrm{MPa}$, heat transfer deterioration disappears. However, when the inner wall temperature, fluid temperature and heat transfer coefficient distributions at $P=4.5 \mathrm{MPa}$ are given in Fig. 24, we found that although the inner wall temperature exceeds the pseudo-critical temperature at $P=4.5 \mathrm{MPa}$, HTD is not observed. As the thermo-physical properties at $P=4.5 \mathrm{MPa}$ is also small, we think the dramatic change of thermo-physical properties is the main reason for the existence of HTD. 

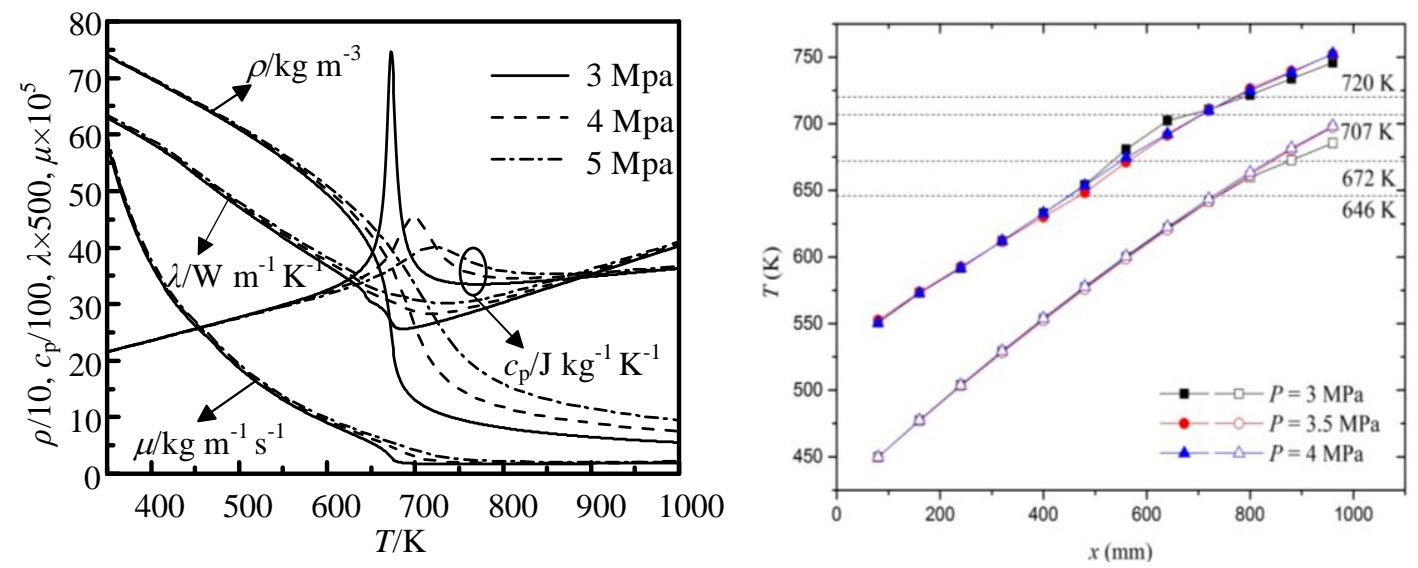

Fig. 18 Variation of the kerosene properties with temperature $(P=3,4$ and $5 \mathrm{MPa})$

Fig. 19 Inner wall temperature (solid symbols) and fluid temperature (hollow symbols) distributions along the tube length under various pressures
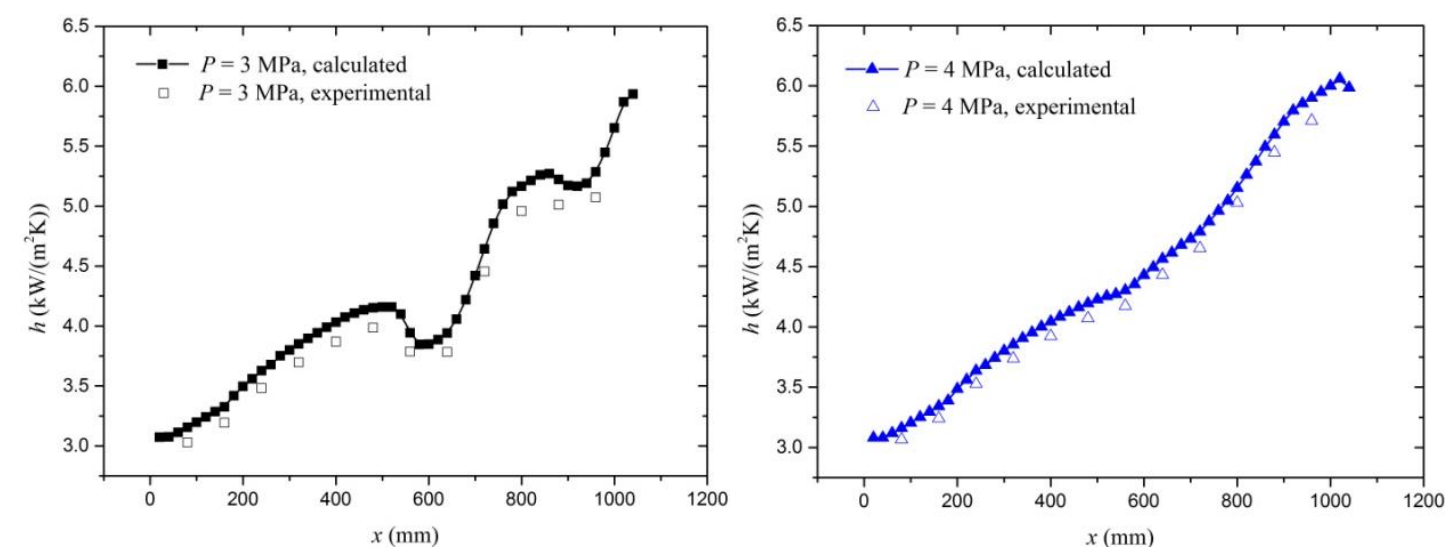

Fig. 21 Comparisons of heat transfer coefficients between numerical simulation and experimental data along the tube length under different pressures

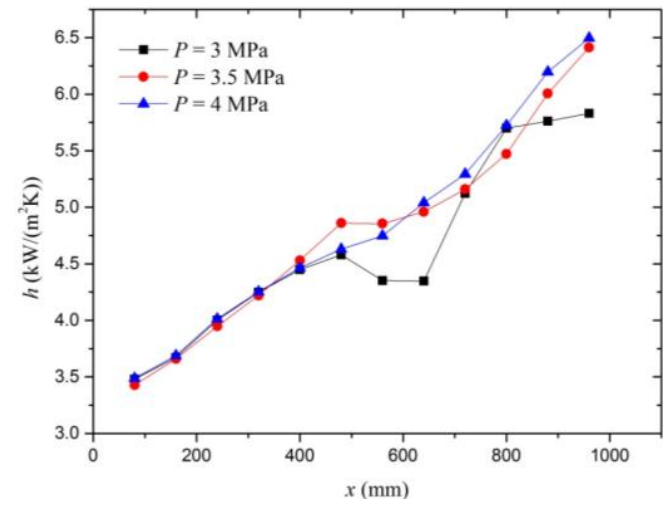

Fig. 20 Heat transfer coefficient distributions along the tube length under various pressures

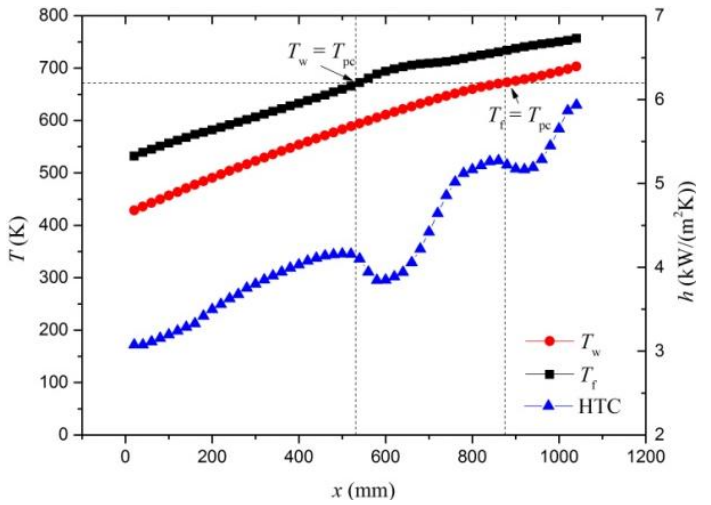

Fig. 22 Fluid temperature, wall temperature and heat transfer coefficient distributions along the tube length at $P$ $=3 \mathrm{MPa}, \quad Q_{\mathrm{m}}=2.21 \mathrm{~g} / \mathrm{s}, \quad q=353 \mathrm{~kW} / \mathrm{m}^{2}, \quad T_{\mathrm{fin}}=421 \mathrm{~K}$ 


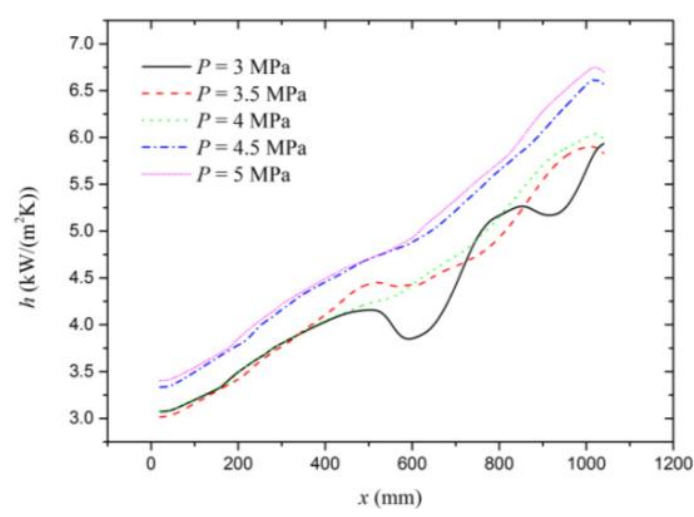

Fig. 23 Heat transfer deterioration under different pressures

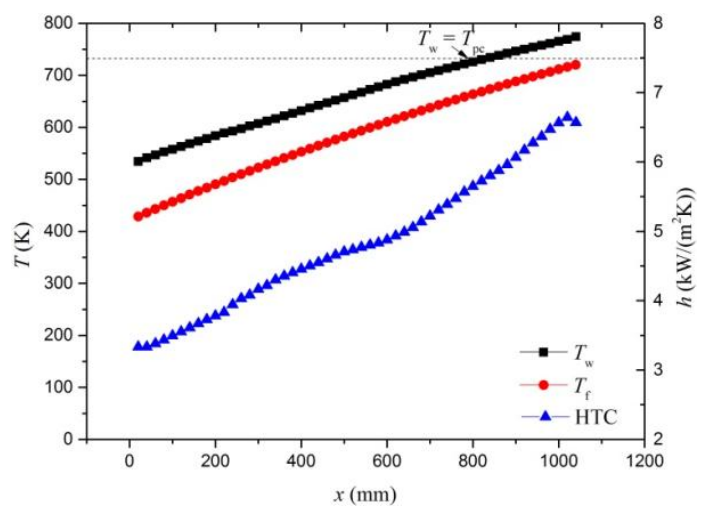

Fig. 24 Fluid temperature, wall temperature and heat transfer coefficient distributions along the tube length at $P$ $=4.5 \mathrm{MPa}, Q_{\mathrm{m}}=2.21 \mathrm{~g} / \mathrm{s}, \quad q=353 \mathrm{~kW} / \mathrm{m}^{2}, \quad T_{\text {fin }}=421 \mathrm{~K}$

\subsection{Inlet temperature effects}

The variation of inlet temperature will influence the temperature distributions along the flow direction, and thus affect the variation of thermo-physical properties. Figures 25 and 26 present the temperature and HTC distributions under various inlet temperatures at $P=3 \mathrm{MPa}$, $Q_{\mathrm{m}}=2.21 \mathrm{~g} / \mathrm{s}$ and $q=319 \mathrm{~kW} / \mathrm{m}^{2}$.

The HTC increases as the inlet temperature increases. The distribution of HTC under different inlet temperature is very similar. HTC first increases, then decreases and then increases again. The decrease in HTC indicates the occurrence of HTD. For $T_{\text {fin }}=448 \mathrm{~K}, T_{\text {fin }}$ $=430 \mathrm{~K}$ and $T_{\text {fin }}=408 \mathrm{~K}$, HTD occurs in the region of $480<x<640 \mathrm{~mm}, 560<x<640 \mathrm{~mm}$ and $640<x<720 \mathrm{~mm}$, respectively. Comparing Fig. 25 and Fig. 26, it is also found that heat transfer is deteriorated at the place where the inner wall temperature exceeds the pseudo-critical temperature.

The comparison between numerical results and experimental data under different pressures is shown in Fig. 27. The numerical data agrees well with the experimental data and the maximum discrepancy is within $10 \%$. The numerical results of inlet temperature effects are shown in Fig. 28. Two types of HTD are both observed, while in the experiment, only HTD I is observed. In the numerical results, HTD I occurs at the place where inner wall temperature exceeds the pseudo-critical temperature, and HTD II occurs at the place where fluid temperature exceeds the pseudo-critical temperature. The effects of inlet temperature on heat transfer deterioration were also investigated in Fig. 29. HTD I and HTD II are both observed for $T_{\text {fin }}=448 \mathrm{~K}$ and $T_{\text {fin }}=468 \mathrm{~K}$. While decreasing inlet temperature, only HTD I is observed. 


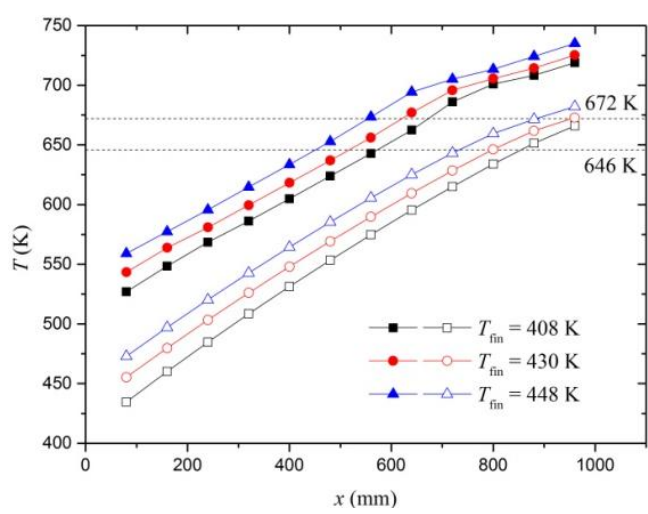

Fig. 25 Inner wall temperaturei (solid symbols) and fluid temperature (hollow symbols) distributions along the tube length under various inlet temperatures
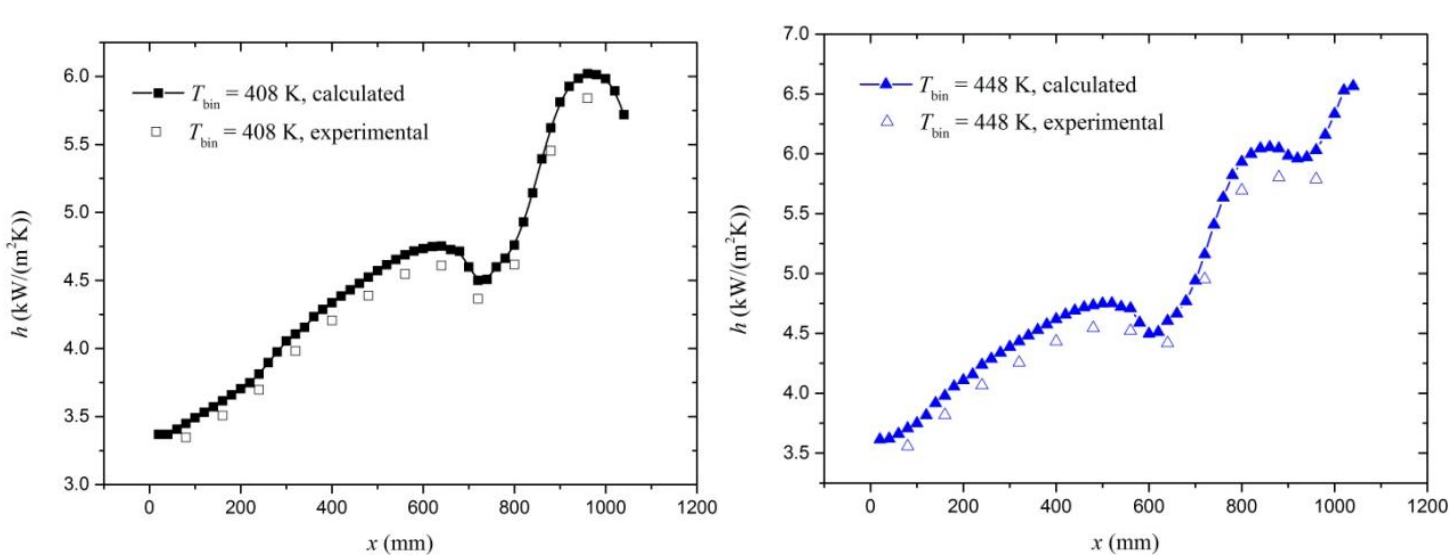

Fig. 27 Comparisons of heat transfer coefficients between numerical simulation and experimental data along the tube length under different inlet temperatures

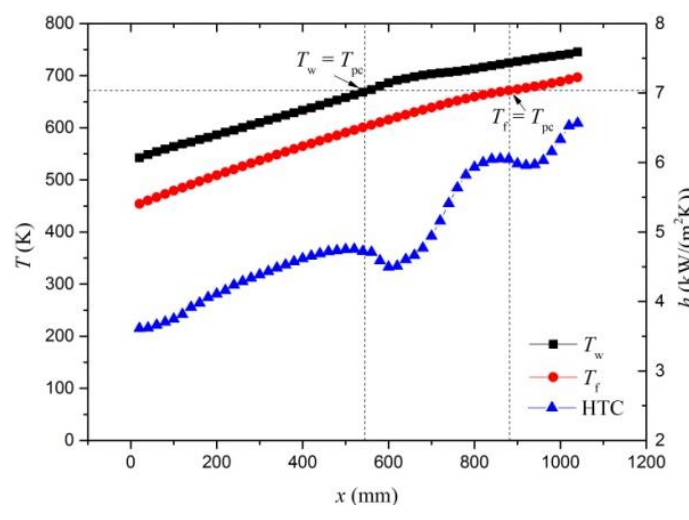

Fig. 28 Fluid temperature, wall temperature and heat transfer coefficient distributions along the tube length at $P$ $=3 \mathrm{MPa}, \quad Q_{\mathrm{m}}=2.21 \mathrm{~g} / \mathrm{s}, \quad q=319 \mathrm{~kW} / \mathrm{m}^{2}, \quad T_{\text {fin }}=448 \mathrm{~K}$

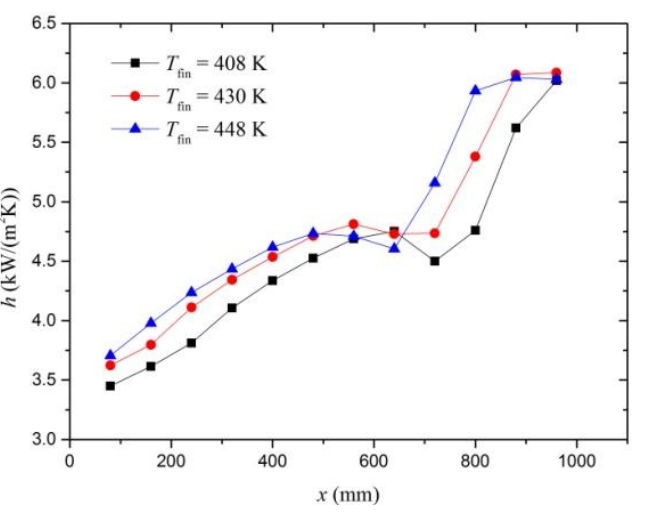

Fig. 26 Heat transfer coefficient distributions along the tube length under various inlet temperatures 
supercritical pressures were investigated experimentally and numerically. Effects of mass flow rate, heat flux, pressure and inlet temperature on heat transfer were given specifically. Main results from this work are summarized as follows:

(1) Heat transfer coefficient increases with increasing mass flow rate and inlet temperature. The effect of heat flux on heat transfer is complicated, while the effects of pressure on heat transfer are insignificant.

(2) Two types of heat transfer deterioration (HTD I and HTD II) were observed in this paper. When the inner wall temperature is larger than the pseudo-critical temperature, HTD I occurs. When the fluid temperature is larger than the pseudo-critical temperature, HTD II occurs.

(3) Heat transfer deterioration is more serious at lower mass flow rate, higher heat flux, higher inlet temperature and lower pressure. Heat transfer deterioration is not only related to the temperature approaching the pseudo-critical temperature, but more related to the changes of thermo-physical properties.

\section{Acknowledgments}

This work is supported by the Scientific Research Foundation for Talented Scholars of CSUFT University (2016YJ002), National Science Foundation of China (51210011) and National Science Foundation of Zhejiang Province, China (LZ13E060001).

\section{References}

[1] Wagner, W.R., Shoji, J.M., Advanced regenerative cooling techniques for future space transportation systems, American Institute of Aeronautics and Astronautics and Society of Automotive Engineers, Propulsion Conference 11th, Anaheim, Calif, 1975

[2] Hua, Y.X., Wang, Y.Z., Meng, H., A numerical study of supercritical forced convective heat transfer of n-heptane inside a horizontal miniature tube, Journal of Supercritical Fluids 52 (2010) 36-46.

[3] Zhong, F., Fan, X., Yu, G., Li, J., Sung, C.J., Heat transfer of aviation kerosene at supercritical conditions, Journal of Thermophysics and Heat Transfer 23 (3) (2009) 543-550.

[4] Deng, H.W., Zhu K., Xu G.Q., Tao, Z., Heat transfer characteristics of RP-3 kerosene at supercritical pressure in a vertical circular tube, Journal of Enhanced Heat Transfer 19 (2012) 409-421. 
[5] Popov, V.N., Petrov, V.E., Calculation of heat transfer and flow resistance in the turbulent pipe flow of cooled carbon dioxide in the supercritical region, Teplofizika Vysokikh Temperature, 23 (1985) 309-316.

[6] Petrov, V.E., Popov, V.N., Heat transfer and hydraulic resistance with turbulent flow in a tube of water at supercritical parameters of state, Therm. Eng. 35 (1988).

[7] Petuhkov, B.S., Heat transfer and friction in turbulent pipe flow, Advances in Heat Transfer 6 (1970) 511-564.

[8] Jackson, J.D., Hall, W.B., Forced convection heat transfer to fluids at supercritical pressure, Turbulent forced convection in channels and bundles 2 (1979) 563-611.

[9] Wang, H., Bi, Q.C., Yang, Z.D., Wang, L.C., Experimental and numerical investigation of heat transfer from a narrow annulus to supercritical pressure water, Ann. Nucl. Energ. 80 (2015) 416-428.

[10] Gang, W., Pan, J., Bi, Q.C., Yang, Z.D., Wang, H., Heat transfer characteristics of supercritical pressure water in vertical upward annuli, Nucl. Eng. Des. 273 (2014) 449-458.

[11] Jiang, P.X., Liu, B., Zhao, C.R., Luo, F., Convection heat transfer of supercritical pressure carbon dioxide in a vertical micro tube from transition to turbulent flow regime, Int. J. Heat Mass Transfer 56 (2013) 741-749.

[12] Li, W., Huang, D., Xu, G.Q., Tao, Z., Zan, W., Zhu, H.T., Heat transfer to aviation kerosene flowing upward in smooth tubes at supercritical pressures, Int. J. Heat Mass Transfer 85 (2015) 1084-1094.

[13] Zhu, J.Q., Tao, Z., Deng, H.W., Wang, K., Yu, X., Numerical investigation of heat transfer characteristics and flow resistance of kerosene RP-3 under supercritical pressure, Int. J. Heat Mass Transfer 91 (2015) 330-341.

[14] Dang, G.X., Zhong, F.Q., Zhang, Y.J., Zhang, X.Y., Numerical study of heat transfer deterioration of turbulent supercritical kerosene flow in heated circular tube, Int. J. Heat Mass Transfer 85 (2015) 1003-1011.

[15] Zhao, G.Z., Song, W.Y., Zhang, R.L., Effect of pressure on thermal cracking of china RP-3 aviation kerosene under supercritical conditions, Int. J. Heat Mass Transfer 84 (2015) 625-632.

[16] Li, X.F., Huai, X.L., Cai, J., Zhong, F.Q., Fan, X.J., Guo, Z.X., Convective heat transfer characteristics of China RP-3 aviation kerosene at supercritical pressure, Appl. Therm. Eng. 31 (2011) 2360-2366. 
[17] Yin, F., Chen, T.K., Li, H.X., An investigation on heat transfer to supercritical water in inclined upward smooth tubes, Heat Transfer Eng. 27 (2006) 44-52.

[18] Kim, J.K., Jeon, H.K., Yoo, J.Y., Lee, J.S., Experimental study on heat transfer characteristics of turbulent supercritical flow in vertical circular/non-circular tubes, Proc. of the 11th Nureth-11, Avignon, France, 2005.

[19] Mokry, S., Pioro, I., Farah, A., King, K., Gupta, S., Peiman, W., Kirillov, P., Development of supercritical water heat-transfer correlation for vertical bare tubes, Nucl. Eng. Des. 241 (2011) 1126-1136.

[20] Huang, D., Wu, Z., Sunden, B., Li, W., A review on convection heat transfer of fluids at supercritical pressures in tubes and the recent progress, Appl. Energy 162 (2016) 494-505.

[21] Gnielinski V. New equations for heat and mass transfer in turbulent pipe and channel flow. International Chemical Engineering 16(2) (1976) 359-368.

[22] Yakhot, V., Orszag, S.A., Renormalization group analysis of turbulence: I, basic theory. J. Sci. Comput. 1 (1986) 1-51.

[23] Dang, G.X., Zhong, F.Q., Chen, L.H., Chang, X.Y., Numerical investigation on flow and convective heat transfer of aviation kerosene at supercritical conditions, Sci. China 56 (2013) 416-422.

[24] Li, X.F., Zhong, F.Q., Fan, X.J., Huai, X.L., Cai, J., Study of turbulent heat transfer of aviation kerosene flows in a curved pipe at supercritical pressure, Appl. Therm. Eng. 30 (2010) 1845-1851.

[25] Deng, H.W., Zhu, K., Xu, G.Q., Tao, Z., Zhang, C.B., Liu, G.Z., Isobaric specific heat capacity measurement for kerosene RP-3 in the near-critical and supercritical regions, J. Chem. Eng. Data 57 (2012) 263-268.

[26] Xu, G.Q., Jia, Z.X., Wen, J., Deng, H.W., Fu, Y.C., Thermal-conductivity measurement of aviation kerosene RP-3 from (285 to 513) K at sub- and supercritical pressures, Int. J. Thermophys 36 (2015) 620-632.

[27] Deng, H.W., Zhang, C.B., Xu, G.Q., Tao, Z., Zhang, B., Liu, G.Z., Density measurements of endothermic hydrocarbon fuel at sub- and supercritical conditions, J. Chem. Eng. Data, 56 (2011) 2980-2986.

[28] Deng, H.W., Zhang, C.B., Xu, G.Q., Zhang, B., Tao, Z., Zhu, K., Viscosity measurements of endothermic hydrocarbon fuel from (298 to $788 \mathrm{~K})$ under supercritical pressure conditions, J. Chem. Eng. Data 57 (2012) 358-365. 
[29] He, S., Kim, W.S., Jackson, J.D., A computational study of convective heat transfer to carbon dioxide at a pressure just above the critical value, Appl. Therm. Eng. 28 (2008) 1662-1675.

[30] Jiang, P.X., Zhang, Y., Zhao, C.R., Shi, R.F., Convection heat transfer of $\mathrm{CO}_{2}$ at supercritical pressures in a vertical mini tube at relatively low Reynolds numbers, Exp. Therm. Fluid Sci. 32 (2008) 1628-1637. 